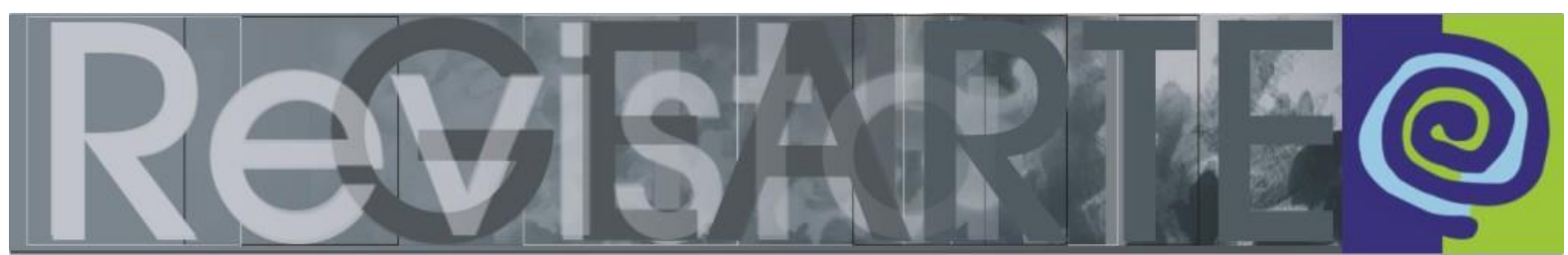

e-ISSN 2357-9854

\title{
Semiótica da arte para deficientes visuais
}

\author{
Fábio Pezzi Parode (Centro Universitário Ritter dos \\ Reis - UniRitter, Porto Alegre/RS, Brasil) \\ Silvia Froemming Pont (Centro Universitário Ritter dos \\ Reis - UniRitter, Porto Alegre/RS, Brasil)
}

RESUMO - Semiótica da arte para deficientes visuais - Este artigo tem como objetivo analisar o recurso de acessibilidade visual disponível no Museo Nacional de Artes Visuales (MNAV) de Montevidéu, Uruguai. Para tal, fez-se uma pesquisa de campo no espaço expositivo, onde foram identificados e delimitados em seu conjunto semiótico, os expositores, as pinturas e os painéis táteis. Especificamente os painéis táteis funcionam como dispositivos de interação sensível para os visitantes com deficiência visual. Tendo como recorte três obras pertencentes ao patrimônio artístico do país, de Juan Manuel Blanes, Carlos Federico Sáez e Joaquín Torres García, propõem-se um comparativo entre as placas de acessibilidade e as pinturas em si, levando em consideração preliminarmente, a abordagem peirciana sobre primeiridade, secundidade, terceiridade e ícone, índice e símbolo.

\section{PALAVRAS-CHAVE}

Acessibilidade visual. Artes visuais. Museo Nacional de Artes Visuales. Semiótica.

ABSTRACT - Semiotics of art for the visually impaired - This article aims to analyze the visual accessibility resource available at the Museo Nacional de Artes Visuales (MNAV) in Montevideo, Uruguay. For this, a field research was carried out in the exhibition space, where the exhibitors, the paintings and the tactile panels were identified and delimited in their semiotic set. Specifically, the tactile panels function as sensitive interaction devices for visually impaired visitors. With three works belonging to the artistic heritage of the country, by Juan Manuel Blanes, Carlos Federico Sáez and Joaquín Torres García, a comparative analysis is proposed between the accessibility panels and the paintings themselves, taking into consideration preliminarily the peircean approach of firstness, secondness, thirdness and icon, index and symbol.

\section{KEYWORDS}

Visual accessibility. Visual arts. Museo Nacional de Artes Visuales. Semiotics.

\section{Introdução}

Os mais antigos registros de comunicação feitos pelo homem, datados da préhistória, eram baseados em imagens. Com o intuito de informar, transmitir ou até manifestar sentimentos, a humanidade construiu uma linguagem unificadora através da representação visual. A imagem é democrática, uma vez que se comunica de forma intuitiva e acessível, diferente da escrita, por exemplo, que requer conhecimento prévio do alfabeto e do idioma utilizados. Segundo Aumont (2012), a experiência cotidiana e a linguagem corrente nos diz que vemos com os olhos, mas é importante 
acrescentar que os olhos são apenas um dos instrumentos da visão, e com certeza não o mais complexo. Para o autor, a visão depende principalmente de operações químicas e nervosas.

Pensando assim, a complexidade da percepção aponta que a imagem possui múltiplas formas de transmitir suas características a um receptor - que não apenas através da visão. É necessário destacar também que "além da capacidade perceptiva, entram em jogo o saber, os afetos, as crenças, que, por sua vez, são muito modelados pela vinculação a uma região da história (a uma classe social, a uma época, a uma cultura)" (AUMONT, 2012, p. 77). Os fenômenos apreendidos pela mente podem se dar de várias formas, e isso exige um estudo um pouco mais aprofundado sobre linguagem e signos. Aqui neste artigo, propomos uma reflexão inicialmente sobre a necessidade fundamental de inclusão social no caso de pessoas com deficiência visual em ambientes culturais, e mais especificamente, sobre a construção dos dispositivos e seus efeitos no espaço formativo da percepção. Neste artigo, buscamos dar inicio a essa pesquisa sem ser exaustivos com relação a temática proposta.

Sendo assim, buscamos traçar uma análise dos recursos táteis de acessibilidade presentes na exposição acervo do Museo Nacional de Artes Visuales de Montevidéu com suas respectivas obras reproduzidas. Para tal, fez-se uma pesquisa de campo no museu, levantando impressões e registros fotográficos. Posteriormente, estes dados foram interpretados com base no estudo de semiologia de Peirce (2002). O artigo divide-se em quatro etapas: 1. Semiótica de Peirce: uma aproximação; 2. Compreensão do campo analisado: o museu; 3. Uma análise com base nos registros; 4 . Considerações finais.

\section{Semiótica de Peirce: uma aproximação}

Charles Sanders Peirce foi um matemático, cientista, lógico e filósofo norteamericano, consagrado mundialmente por ser o fundador e precursor da semiologia. A semiologia, por sua vez, estuda qualquer fenômeno cultural como um sistema sígnico - um sistema provido de significação. Segundo Santaella (2002), a semiologia de Peirce é um dos membros da tríade das ciências normativas, estética, ética e lógica, estas antecedidas pela "quase-ciência" da fenomenologia e seguidas pela 
metafísica. Essa "quase-ciência" serve para investigar os modos como apreendemos qualquer coisa que aparece à nossa mente, "algo simples como um cheiro, uma formação de nuvens no céu, o ruído da chuva, uma imagem em uma revista etc., ou algo mais complexo como um conceito abstrato, a lembrança." (SANTAELLA, 2002, p. 2). Neste ponto é necessário frisar que Pierce apresenta uma semiologia que engloba quaisquer princípios sígnicos de várias naturezas, não se limitando apenas à linguagem verbal, como é a proposta de estudo dos signos sugerida pela linha estruturalista francesa de Saussure, por exemplo.

Com base em seus estudos sobre fenomenologia, Peirce conclui que há três elementos formais e universais em todos os fenômenos que se apresentam à mente, aos quais nomeou de primeiridade, secundidade e terceiridade. Fazendo uma breve análise, pode-se afirmar que estas categorias representam, respectivamente, o sentir, o perceber e o entender. A forma mais simples da terceiridade, segundo Peirce, manifesta-se no signo, visto que o signo é um primeiro (algo que se apresenta à mente), ligando um segundo (aquilo que o signo indica) a um terceiro (o efeito que o signo irá provocar em um possível intérprete), e pode se apresentar de várias formas, como sugere Santaella:

Em uma definição mais detalhada, o signo é qualquer coisa de qualquer espécie (uma palavra, um livro, uma biblioteca, um grito, uma pintura, um museu, uma pessoa, uma mancha de tinta, um vídeo etc.) que representa uma outra coisa, chamada de objeto do signo, e que produz um efeito interpretativo em uma mente real ou potencial, efeito este que é chamado de interpretante do signo. (SANTAELLA, 2002, p. 8)

É possível usar de exemplo uma obra de arte, como será explorado mais a frente: o primeiro contato que se tem é referente à cor, forma e material, livre de préconceitos, que aquela obra é composta, o segundo se relaciona com o que ela está apresentando, se é uma obra figurativa ou não, por exemplo, e o terceiro é a sua representação, permitindo assim uma interpretação por parte do espectador. A relação do signo com seu objeto (aquilo que o signo representa) é uma fonte de indefinição na extensão ou aplicabilidade do signo e a relação do signo com o interpretante (o efeito que o signo produz na mente que o interpreta) é uma fonte de indefinição na profundidade do signo. O signo deixa para o intérprete o direito de completar a determinação por si mesmo (SANTAELLA, 1992). 
Para explorar esse potencial comunicativo, a semiótica propõe três pontos de vista complementares, que serão peça-chave na análise das obras neste artigo: o qualitativo-icônico (referencia-se a qualidade da matéria, do que é feito suas cores, linhas, volume, dimensão, textura, forma, etc.), o singular-indicativo (algo que existe em um espaço e tempo determinados, ou seja, o contexto ao qual aquele signo pertence) e o convencional-simbólico (não se mostra mais em sua singularidade, mas também no seu poder representativo, como valores culturais) (SANTAELLA, 2002).

\section{Compreensão do campo analisado: o museu}

O Museo Nacional de Artes Visuales (MNAV) de Montevidéu foi criado em 1911 e está localizado no Parque Rodó, oferecendo visitação gratuita de terça a domingo. Possui um acervo de mais de seis mil obras, especialmente de artistas nacionais, apresentando a maior e mais importante coleção artística do patrimônio uruguaio. A exposição Colección MNAV faz um recorte dessas obras, passando por diferentes períodos como o modernismo e a contemporaneidade. Segundo a coordenadora do setor educativo, Maria Eugenia Grau, essa seleção de obras tem como objetivo manifestar as "múltiplas possibilidades de leitura da produção artística do Uruguai, emergindo assim o debate dos fluxos de uma sociedade nos seus diferentes momentos de desenvolvimento" (GRAU, 2016). Um dos pontos fundamentais para esta pesquisa a se observar é o fato de que a comunicação com a sociedade foi feita de forma inclusiva e acessiva.

Para Lidwell et al (2010), um dos princípios universais do design é o da acessibilidade, que prevê a projetação dos ambientes visando que estes sejam utilizados pelo maior número de pessoas possível. A história mostra que a acessiblidade estava concentrada em acomodar usuários com deficiências e, ao longo do tempo, foi percebido que as "adaptações" poderiam ser projetadas desde o início, para o benefício de todos usuários. Ou seja, se a acessibilidade for uma preocupação ainda na raiz do projeto, esta será incorporada e utilizada com mais facilidade no cotidiano. Trata-se de uma cultura de projeto a ser desenvolvida e ampliada, em que os princípios de design universal, especialmente a inclusão social, são incorporados já no processo de projeto. Segundo Farina et al (2011), qualquer coisa que provoca uma reação em algum órgão do sentido é considerado um estímulo. Quando um 
indivíduo responde a um estímulo determinado é porque o percebeu entre outros. Para os autores, a percepção é um processo que se baseia na ação, na probabilidade e na experiência. A imagem que percebemos é um dos elementos desse processo.

O estímulo aqui abordado será o tátil, ainda que também exista o sonoro. $\mathrm{Na}$ frente de cada obra exposta no MNAV, há um pedestal com duas alternativas sensoriais referentes às obras: um áudio-descritivo a ser acionado via bluetooth no telefone celular, mais comumente encontrado em espaços expositivos, e uma reprodução da obra em relevos, feita de metal, para que se possa reconhecer a forma através do toque. É importante salientar a presença de piso tátil no decorrer das obras, possibilitando uma visitação não apenas mais rica, mas também autônoma para o deficiente visual. Essas tecnologias de acessibilidade e inclusão são resultados de projetos de design, cuja base estrutura-se nos princípios da cidadania e da universalidade. Há portanto, uma clara posição politica na relação design e sociedade, buscando sobremaneira o desenvolvimento e a qualificação das relações humanas e da democracia. Acredita-se, portanto, e esta é uma prerrogativa do design social e cultural, que o design é um agente transformador da realidade e pode ativar a sensibilidade e a percepção de forma qualificada com relação ao conjunto que compõe os planos de exterioridade e coletividade. Abaixo, mostraremos o espaço museal com suas tecnologias de inclusão. Note-se que a simples presença do dispositivo alternativo que permite outra leitura das obras, já implementa de forma significativa a presença da diferença, no caso, de pessoas portadoras de necessidades especiais. O pequeno espaço do museu passa a comportar, enquanto microcosmo, um padrão de inclusão que, no limite, das práticas educativas e institucionais, promove o convívio social qualificado e inclusivo, em outros ambientes. Sobretudo, um museu é uma tecnologia de educação e formação cultural. 


\section{Figura 1 - Exposição Colección MNAV}

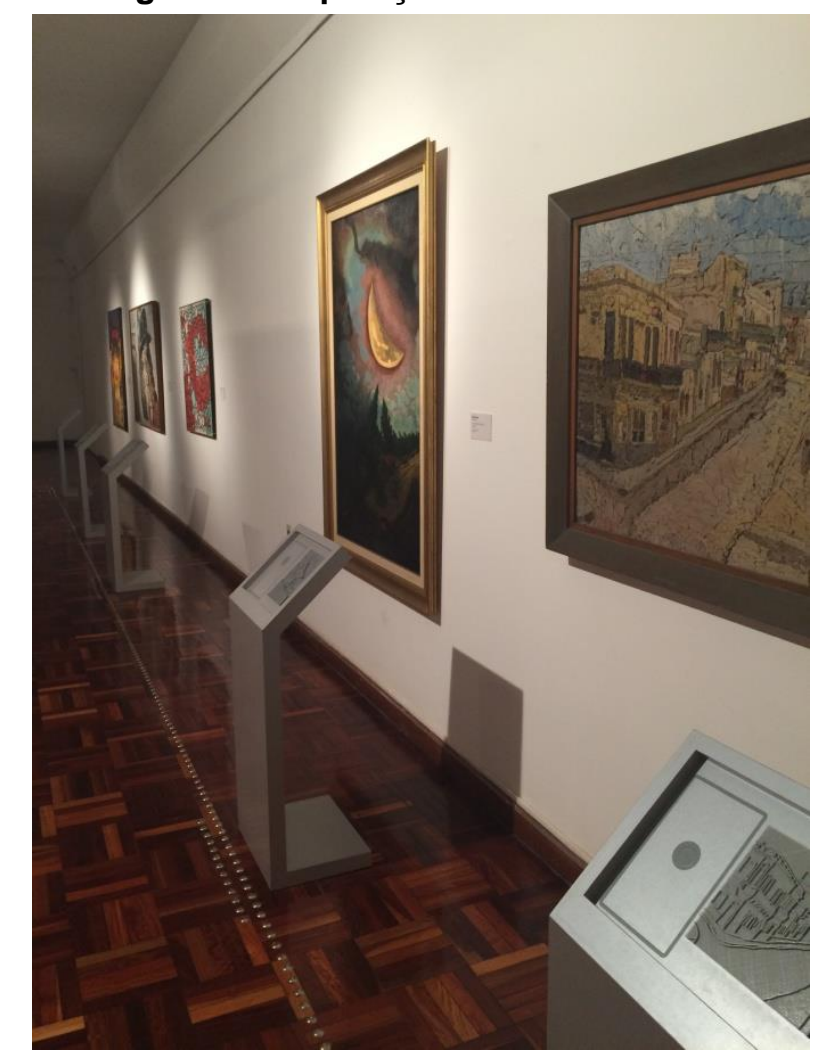

Fonte: acervo fotográfico de Fábio Pezzi Parode, 2016.

\section{Uma análise com base nos registros}

A análise foi efetuada a partir de registros fotográficos de Fábio Pezzi Parode durante a exposição, em janeiro de 2016. Para a análise foram selecionadas três pinturas de diferentes artistas nacionais a fim de explorar os elementos universais definidos anteriormente por Peirce, traçando um comparativo entre o sensorial tátil das obras e seus elementos picturais de composição. 


\section{Análise da obra Un episodio de la fiebre amarilla en Buenos Aires}

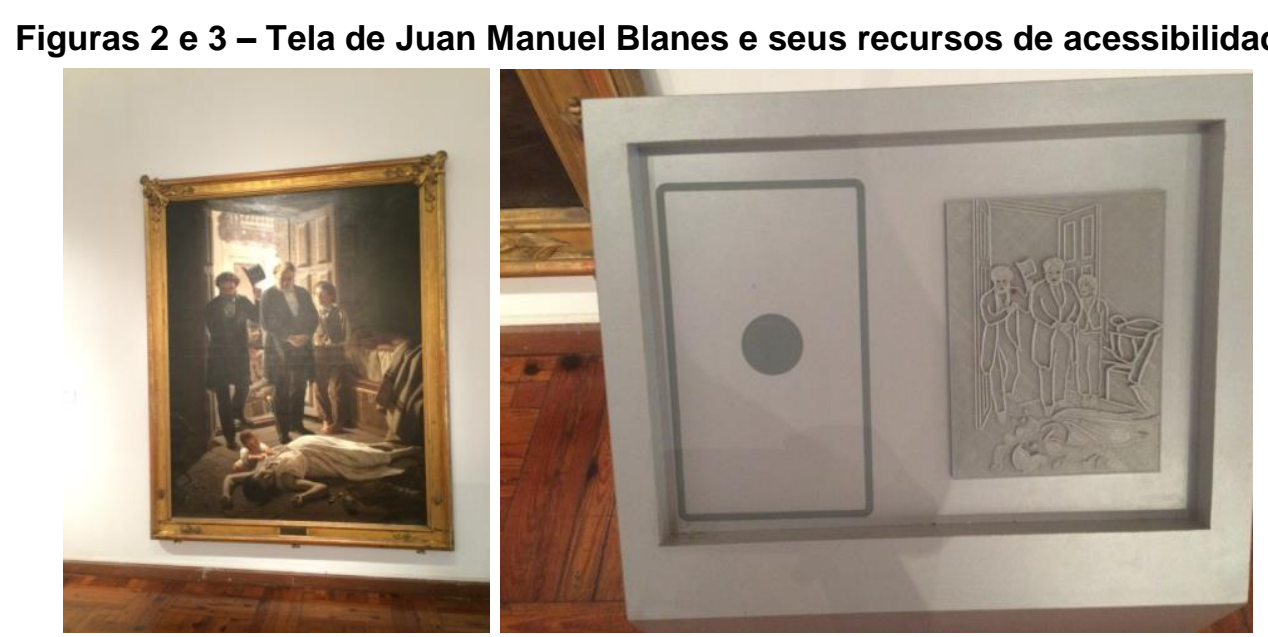

Fonte: acervo fotográfico e composição de Fábio Pezzi Parode, 2016.

Uma das mais conhecidas obras do pintor uruguaio Blanes (1830-1901), ficou exposta durante dois anos no saguão do Teatro Colón, em Buenos Aires. Blanes era reconhecido por interpretar temas históricos locais, tanto no Uruguai quanto nos países em que viveu. Em um primeiro acesso, na análise qualitativa, percebe-se um quadro com grandes dimensões e paleta escura, transmitindo-nos uma impressão de sobriedade e pesar. As linhas claras e definidas que compõem a obra são reproduzidas em relevo no metal permitindo, através do toque, a percepção da forma. Não há como representar as cores, mas as figuras em sua linearidade, permitindo uma aproximação do conteúdo, mesmo que limitado aos portadores de deficiências visuais. A iconicidade é garantida pelo conjunto semiótico que sugere uma representação na mente, um signo que pode transmitir um conteúdo. Há, portanto, a possibilidade de leitura sensorial pelo tato e não pela visão. Juntamente com a sonoridade, os organizadores da exposição buscam preencher o vazio ocasionado pela ausência de visão. Não há luz, mas há presença, materialidade e essa materialidade dentro de sua organização, programada inicialmente pelo artista, é transcrita com a linguagem em relevo das linhas no metal, permitindo a codificação necessária para compor o texto e a narrativa proposta pelo artista.

$\mathrm{Na}$ tela, as tintas em sua composição remetem a um jogo de luz e sombra, organizando as massas a induzirem a percepção de imagens, figuras humanas e ambientes. A sugestão de espaço é pouco iluminada, há predominância de cores 
sombrias, remetendo à imagem de um pequeno quarto em meio à escuridão. Entretanto, um facho de cor branca, simulando luz é evidenciado por uma tonalidade amarelada proveniente de um ponto de fuga na parte superior da superfície da tela. Ainda na tela, em nível de secundidade, ao fazer traçar um detalhamento maior, é possível identificar algumas figuras humanas, dentre elas, dois homens de terno que encaram uma mulher deitada ao chão, possivelmente morta, sendo amparada por um bebê. O foco de iluminação é a mulher, que veste branco, alavancando-a como protagonista na pintura. Na placa metálica, o escuro das paredes e do fundo da tela confunde-se com o escuro das roupas dos retratados, que é evidenciado na representação em metal por linhas: as tonalidades escuras são representadas por linhas vazadas e as mais claras, por formas de relevo preenchidas, facilitando a distinção. As expressões dos rostos também são apresentadas pela ausência do relevo, transmitindo o sentimento dos observadores sobre a mulher jazida.

Em nível de terceiridade, relacionando a obra com aspectos culturais e sociais, indo ao encontro de uma interpretação sobre o que a obra representa, associamos as imagens com a cena de morte. Ao conhecer a trajetória do artista através de uma rápida consulta em páginas de enciclopédia online, descobre-se que este morou em Buenos Aires durante o período de expansão da febre amarela na população, fazendo com que essa representação possivelmente trate-se de um tema cotidiano na época. Ao percorrer os dedos sobre a reprodução em metal de poucos centímetros e perceber, aos poucos, o que ela transmite, dá uma mais completa noção da sensação de sofrimento representada na obra de $230 \times 180 \mathrm{~cm}$. A obra em sua perspectiva sincrônica, nos leva a presença trágica da morte no cotidiano causada pela epidemia, levando-nos ao confronto triste de vidas ceifadas pela doença. 


\section{Análise da obra Estudio:}

Figuras 4 e 5 - Tela de Carlos Federico Sáez e seus recursos de acessibilidade.

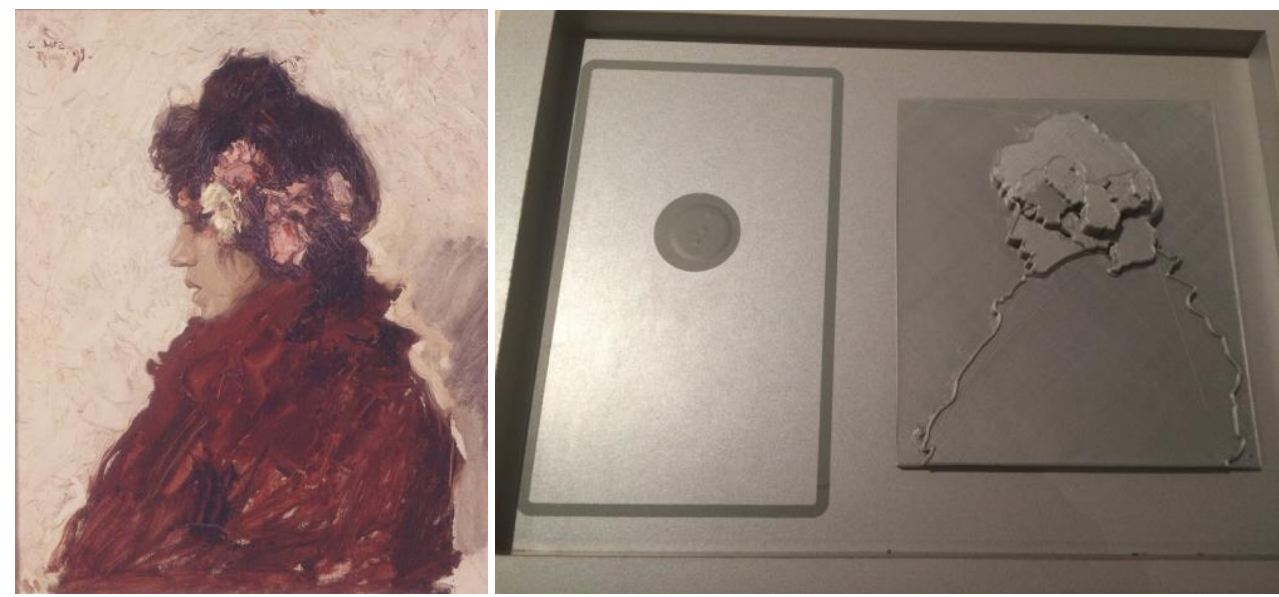

Fonte: registro fotográfico e composição de Fábio Pezzi Parode, 2016.

$\mathrm{Na}$ fase qualitativa-icônica da percepção, nota-se uma paleta semelhante de cores difusas, entre vermelho, rosa, rebu, marrom e demais tons terrosos, dispostos em uma tela na posição paisagem. Com a atenção singular-indicativa, percebe-se a representação figurativa de um perfil feminino, porém com traços borrados, abertos, não-lineares. Essa figura feminina está usando um coque com flores no cabelo e uma veste vermelha escura, também representada de forma pouco precisa com pinceladas largas e sem contorno. As flores, o rosto, o cabelo e a expressão confundem-se tanto na tonalidade semelhante das cores quanto na ausência de linhas que demarquem estes espaços.

Na transcrição dessa obra para a representação tátil em metal, fica evidente a preocupação em demarcar esses detalhes devido à complexidade da estrutura formal, quanto mais abstrato o quadro, mais complexa a transcrição no metal. Assim, para esta pintura foram criadas cinco camadas sobrepostas de relevo preenchido para delimitar tais contornos esmaecidos. O perfil feminino também foi traçado para apontar a presença de nariz e boca, aludindo à forma humana. O fundo, composto basicamente pela veste e a parede, diferencia-se com apenas uma linha - que transmite determinada expressividade, na tentativa de simular o gesto irregular das pinceladas. Da mesma forma que uma pintura cuja representação é simplificada por grafismos, o design universal, na medida em que delimita um padrão reduzido na ordem da expressão, torna-se básico, pretensamente universal. A não linearidade, o 
abstrato criam desafios a transcrição do sentido em relevo para os deficientes visuais. No entanto, em termos de visualidade, a simplificação traz outros fatores comprometedores, tais como o reducionismo e o pouco estímulo às novas percepções. A arte minimal é um exemplo de formas simplificadas que no âmbito da expressão não estimulam a imaginação, ao contrário, apresentam-se como formas fechadas e básicas.

\section{Análise da obra Grafismo infinito}

Figuras 6 e 7 - Tela de Joaquín Torres García e seu recurso de acessibilidade
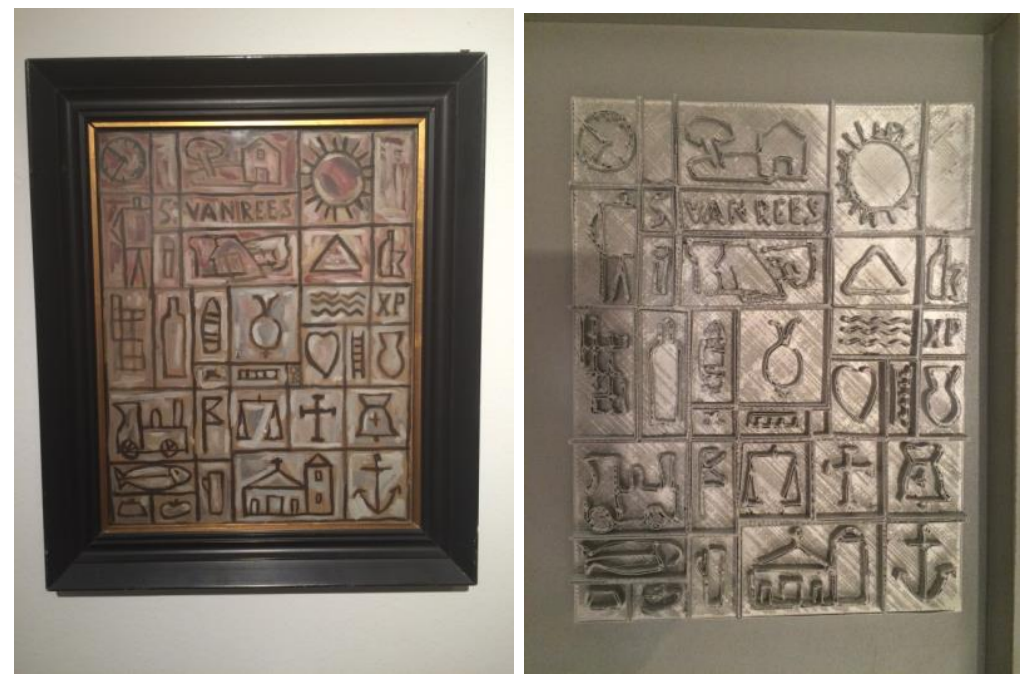

Fonte: registro fotográfico e composição de Fábio Pezzi Parode, 2016.

Pela simplicidade do traço de Torres García, talvez esta seja a mais fidedigna obra analisada em relação ao seu painel tátil, uma vez que o traço do autor se aproxima do sistema de ícones, ou até mesmo da escrita. Essa proximidade provoca uma relação facilitadora entre sujeito e objeto, uma vez que estas representações, textual e icônica, estão muito presentes no cotidiano.

$\mathrm{Na}$ percepção qualitativa apresentam-se tons marrons e acinzentados, representando figuras em uma tela pequena. Em uma análise mais cuidadosa, é possível observar elementos geometrizados de representações cotidianas das mais diversas, como um sol, uma âncora, uma garrafa, uma cruz, um peixe, um trator, um triângulo, uma igreja, etc. Através do caráter convencional-simbólico, nota-se o artista como um observador da vida em sua época, seus costumes e lidas. O painel tátil apresenta alto nível de verossimilhança com sua obra representada, tendo em vista a 
facilidade em transpor o traço do artista para tal suporte. Os tons de cores, porém, não aparecem devido à grande quantidade de detalhes nos desenhos traçados. A diferença mais marcante são os tons claros e escuros para delimitar a profundidade dos planos em relevo.

\section{Considerações finais}

A acessibilidade democratiza o acesso universal à cultura e ao conhecimento oferecendo, ainda, um adicional ao sensorial daqueles que não necessitam de artífices para a inclusão. $\mathrm{Na}$ análise semiótica dos painéis foi percebida a importância de um suporte tátil atrelado ao áudio-descritivo já presente em alguns museus, uma vez que este sozinho jamais transmitirá a real composição dos elementos retratados. Em uma análise mais profunda, nenhum dispositivo vai dar conta de todos os aspectos, uma vez que a representação é sempre falha - se o signo está, é porque o que é representado, falta. Por exemplo, ao descrever de forma individual os elementos de um quadro, como na obra de Torres García, "um sol, uma âncora, uma garrafa, ...", não é possível distinguir onde está representado cada um dos elementos em relação ao outro. A noção espacial através do estímulo sensorial do tato é fundamental para que se amplie a experiência e se compreenda a obra como um todo - e não elementos separados.

A semiótica peirceana, que engloba essas várias formas de linguagem, auxilia na percepção e, até mesmo, na confecção de complementares experienciais, uma vez que encara, passo a passo, suas nuances e elementos. Dessa forma, a percepção das categorias universais em Peirce, ícone, índice e símbolo, ou primeiridade, secundidade e terceiridade, nos possibilita no nível do projeto compor de forma inclusiva, elaborando estratégias que possam estimular a sensação, expandindo a percepção através de outros elementos que não apenas o visual. Dessa forma, o designer pode funcionar como agente integrador entre as diferentes linguagens operando nos âmbitos social e cultural, buscando abranger uma totalidade das diferenças humanas sem contudo ser reducionista, ao contrário, buscando incrementar e trazer novos elementos para compor o universo sistêmico das relações humanas e suas semioses. 


\section{Referências}

AUMONT, Jacques. A imagem. 16ª ed. Campinas, SP: Papirus, 2012.

FARINA, Modesto; PEREZ, Clotilde; BASTOS, Dorinho. Psicodinâmica das cores em comunicação. $6^{\underline{a}}$ ed. São Paulo: Blucher, 2011.

GRAU, Maria Eugenia. Texto curatorial da Exposição Colección MNAV. MNAV, 2016.

LIDWELL, William; HOLDEN, Kritina; BUTLER, Jill. Princípios universais do design. Porto Alegre: Bookman, 2010.

SANTAELLA, Lucia. Semiótica aplicada. São Paulo: Pioneira Thomson Learning, 2002.

SANTAELLA, Lucia. A assinatura das coisas: Peirce e a literatura. Rio de Janeiro: Imago Ed., 1992.

\section{Fábio Pezzi Parode}

Doutor em Estética pela Université de Paris 1 - Panthéon Sorbonne (2005), Mestre em Ciências da Comunicação pela Universidade do Vale do Rio dos Sinos (UNISINOS, 2000), Especialista em Design Estratégico pela UNISINOS (2008), graduação em Comunicação Social Jornalismo pela Pontifícia Universidade Católica do Rio Grande do Sul (PUCRS, 1992). Tem experiência na área de Comunicação, com ênfase em Estética e Comunicação, atuando principalmente nos seguintes temas: arte, estética e comunicação, comunicação visual e design. É professor pesquisador em Design, Artes Visuais e Estética. Realiza pesquisa sobre tendências em design, estética e sustentabilidade. Foi editor do periódico científico Strategic Design Research Journal, www.unisinos.br/sdrj, de 2008 até 2015. É membro do Grupo de pesquisa cadastrado no CNPq Paradigmas, Teorias, Conceitos, Materiais, Poiéticas e Poéticas: Questões Constitutivas da Pintura Contemporânea, liderado pela profa. Dra. Icleia Borsa Cattani - UFRGS; membro do Grupo de Pesquisa em Semiótica e Culturas da Comunicação (GPESC/CNPq), liderado pelo prof. Dr. Alexandre Rocha da Silva - UFRGS; e membro do Grupo de Pesquisa cadastrado no CNPq Design Estratégico: Inovação Cultural e Social, liderado pela profa. Dra. lone Bentz - UNISINOS.

E-mail: fparode@gmail.com

Currículo: http://lattes.cnpq.br/2559908721277242

\section{Silvia Froemming Pont}

Possui graduação em Design Gráfico pelo Centro Universitário Ritter dos Reis (2012) e atualmente cursa o mestrado em design na mesma instituição. Membra do Grupo de Pesquisa em Semiótica e Culturas da Comunicação (GPESC/CNPq), liderado pelo prof. Dr. Alexandre Rocha da Silva - UFRGS. Atuou como arte-educadora em exposições de arte moderna e contemporânea. Desenvolve projetos na área de criação e diagramação de impressos.

E-mail: silpont@gmail.com

Currículo: http://lattes.cnpq.br/6169506514509991

Recebido em 13 de junho de 2017 Aceito em 23 de novembro de 2017 